Article

\title{
Precision Manufacturing of Patterned Beryllium Bronze Leaf Springs via Chemical Etching
}

\author{
Rui-Jun Li 1,* (D), Peng-Yu Wang ${ }^{1}$, Dan-Dong Li ${ }^{1}$, Kuang-Chao Fan ${ }^{1,2}$ (D), Fang-Fang Liu ${ }^{1}$, \\ Li-Juan Chen ${ }^{1}$ and Qiang-Xian Huang ${ }^{1}$ (iD \\ 1 School of Instrument Science and Opto-electronics Engineering, Hefei University of Technology, \\ Hefei 230009, China; 2016110023@mail.hfut.edu.cn (P.-Y.W.); \\ lidandong@mail.hfut.edu.cn (D.-D.L.); fan@dlut.edu.cn (K.-C.F.); liuff@hfut.edu.cn (F.-F.L.); \\ chenlj@hfut.edu.cn (L.-J.C.); huangqx@hfut.edu.cn (Q.-X.H.) \\ 2 School of Mechanical Engineering, Dalian University of Technology, Dalian 116024, China \\ * Correspondence: rj-li@hfut.edu.cn; Tel.: +86-551-62901508
}

Received: 30 June 2018; Accepted: 22 August 2018; Published: 28 August 2018

Featured Application: Fabrication of high-precision patterned leaf springs or membranes for measuring equipment.

\begin{abstract}
Patterned leaf springs made of a beryllium bronze sheet are the key components of certain micro/nano contact probes. The accuracy of the probe is determined based on the precision of the formed pattern. However, a traditional manufacturing method using wire-electrode discharge machining (wire-EDM) is subject to poor tolerance at the sharp edges and corners. In addition, high energy consumption and costs are incurred for complex patterns. This paper presents a new chemical etching method for the manufacturing of a patterned leaf spring with high precision. Both the principle and process are introduced. Taguchi experiments were designed and conducted and the optimal process parameters were obtained based on the mean value and a variance analysis. Four V-shaped and some other complex patterned leaf springs were successfully fabricated. Comparison experiments concerning the characteristic parameters of the leaf spring were also conducted. The experimental results reveal that the patterned leaf springs manufactured through this method are much better than those achieved using wire-EDM. This manufacturing method can be used to fabricate different high-precision patterned leaf springs or membranes for coordinate measuring machines (CMM) probes and other measuring equipment.
\end{abstract}

Keywords: probe; leaf spring; chemical etching; beryllium bronze

\section{Introduction}

During the past two decades, a variety of micro-electromechanical systems (MEMS) have been fabricated through the rapid development of precision and ultra-precision machining technologies. Liu et al. (1999) described two microthermal shear-stress sensors, in which high aspect ratio cavities of $(200 \times 250) \mu \mathrm{m}(2) \times 400 \mu \mathrm{m}$ were fabricated using bulk silicon substrate etching and anodic bonding technology [1]. Alshehri et al. (2013) developed micro hot-film shear-stress sensors using surface micromachining techniques and fabricated a micro silicon-nitride diaphragm and polycrystalline silicon heat-sensing element [2]. Therefore, micro/nano measurement equipment is required to assess the fabricating quality of micro devices. The leaf spring is often used as a key component of high-precision measuring instruments, or micro-actuators, when an elastic and recoverable micromotion is required, such as the cantilever beam used in atomic force microscopy (AFM). Claverley et al. (2010) and Li et al. (2014, 2016 and 2016) developed several probing systems for micro/nano CMMs [3-5]. 
Leaf springs are used to transfer the 3D displacements of the ball tip into the motions of a mirror in a vertical translation and horizontal rotation. The performance of the leaf spring directly determines the repeatability, stiffness and isotropy of the probe. Because the beryllium bronze sheet used as an elastic membrane has better repeatability and stiffness, it is a more suitable material for the fabrication of patterned leaf springs. The flatness and edge uniformity of a leaf springs mainly affect the probe's repeatability. The higher the flatness and uniformity, the better the repeatability. The size precision of a leaf springs mainly affects the probe's stiffness and isotropy. According to the Equation (1) or Equation (2) in Reference [3], we can obtain that the relative change of the stiffness or anisotropy is less than $0.5 \%$ when the four V-shaped leaf spring's width have an error of $10 \mu \mathrm{m}$. Therefore, the target manufacturing accuracy of a leaf springs can be controlled in $\pm 10 \mu \mathrm{m}$.

A common method for fabricating beryllium bronze leaf springs is wire-electrode discharge machining (wire-EDM), which produces a better edge quality than laser cutting. However, we found that wire-EDM still cannot satisfy the high-precision manufacturing requirements of a leaf spring owing to the following disadvantages: (1) poor edge uniformity and a large offset, (2) processing heat and anisotropic stress causing a deformation of the fabricated leaf spring, (3) difficulty in fabricating leaf springs with complex patterns and (4) a high cost. Other methods can be used to process beryllium bronze. For example, Liu et al. (2002) described a lithography technology for microstructure fabrication and fabricated micro-capillaries and a micro-valve [6]. Tajiri et al. (2001) described an electrotyping technology, which they used to develop a copper lining for RF (Radio frequency) cavity sputtering [7]. Schindler et al. (2001) summarized the fabrication of 3D micro-optical resist structures (e.g., micro-lens arrays and blazed Fresnel lens structures) using hard optical and optoelectronic materials through ion beam and plasma jet etching technology [8]. Finally, Bodeux et al. (2014) fabricated tetragonal tungsten bronze using RF magnetron sputtering [9]. Although high precision and a small size can be achieved through these methods, their practicality for the fabrication of leaf springs remains limited owing to high costs, low efficiency and difficult operations.

Aiming at the shortcomings of above methods, a chemical etching method that can be used to fabricate a beryllium-bronze based leaf spring was adopted for this study. This method is based on the chemical reaction of copper $(\mathrm{Cu})$ with sodium persulfate $\left(\mathrm{Na}_{2} \mathrm{~S}_{2} \mathrm{O}_{8}, 2017\right.$, Taishan Chemical Factory Co., Ltd., Taishan, China). The advantages of this method include (1) high precision, (2) a lack of thermal and stress deformations, (3) easy operation and the ability to fabricate complex leaf spring patterns, (4) low energy consumption and (5) low cost. The results of a comparison of the different manufacturing methods available are summarized in Table 1 [10-14].

Table 1. Comparison of different manufacturing methods.

\begin{tabular}{|c|c|c|c|c|c|c|}
\hline Item & Lithography & Electrotyping & Sputtering & $\begin{array}{l}\text { Wire-Electrode Discharge } \\
\text { Machining (EDM) }\end{array}$ & Laser Cutting & Chemical Etching \\
\hline precision & $<10 \mathrm{~nm}$ & $\leq 0.5 \mu \mathrm{m}$ & $10 \mathrm{~nm}$ & 5-20 $\mu \mathrm{m}$ & $50 \mu \mathrm{m}$ & $<10 \mu \mathrm{m}$ \\
\hline deformation & no & non-uniform thickness & no & thermal and stress & thermal and stress & no \\
\hline complex patterns & easy & easy & easy & difficult & easy & easy \\
\hline equipment cost (\$) & $80,000+$ & $1500+$ & $15,000+$ & $1500+$ & $1500+$ & $150-$ \\
\hline power $(\mathrm{kW})$ & $1-100$ & $3-10$ & $3-20$ & $2-5$ & $2-10$ & $<0.6$ \\
\hline operation & very complex & very complex & very complex & complex & complex & very simple \\
\hline space usage $\left(\mathrm{m}^{2}\right)$ & $>50$ & $>50$ & $>50$ & $10-15$ & $10-15$ & $<5$ \\
\hline production periodic & $>5 \mathrm{~h}$ & $>5 \mathrm{~h}$ & $>5 \mathrm{~h}$ & $<1 \mathrm{~h}$ & $<1 \mathrm{~h}$ & $\leq 2 \mathrm{~h}$ \\
\hline
\end{tabular}

\section{Principle and Process Flow}

\subsection{Principle}

The grade of the beryllium bronze sheet used in this study is C17200. The beryllium bronze's main element is $\mathrm{Cu}$, other gradient includes: beryllium (1.9-2.15\%), cobalt $(0.35-0.65 \%)$, nickel $(0.2-0.25 \%)$, silicon $(<0.15 \%)$, iron $(<0.15 \%)$ and aluminum $(<0.15 \%)$. Cu can be corroded through a solution of $\mathrm{Na}_{2} \mathrm{~S}_{2} \mathrm{O}_{8}$. The chemical reaction equation is as follows:

$$
\mathrm{Cu}+\mathrm{Na}_{2} \mathrm{~S}_{2} \mathrm{O}_{8}=\mathrm{CuSO}_{4}+\mathrm{Na}_{2} \mathrm{SO}_{4}
$$


A beryllium bronze sheet is always used as the raw material of a leaf spring. A photoresist film (negative photosensitive material) can be used to protect the beryllium bronze sheet from corroding. The photoresist film used to cover a beryllium bronze sheet has to conform to the pattern of the designed leaf springs in advance. Therefore, the part of a beryllium bronze sheet with a photoresist film will be protected and maintained, whereas other parts will be etched off in a $\mathrm{Na}_{2} \mathrm{~S}_{2} \mathrm{O}_{8}$ solution. Thus, patterned leaf springs can be obtained.

\subsection{Process Flow}

The process flow of this method consists of eight steps, namely, the pattern design, mask printing, pretreatment, pasting of photo-sensory membranes, exposure, development, etching and mold unloading, the details of which are as follows.

(1) Pattern design.

According to the actual demand of a particular type of measuring equipment, it is necessary to design the pattern of the leaf springs first and to then analyze and optimize the structural parameters of the pattern. Li et al. (2014) designed a four V-shaped suspending leaf spring pattern (shown in Figure 1) for their 3D contact-scanning probe $[3,15]$.

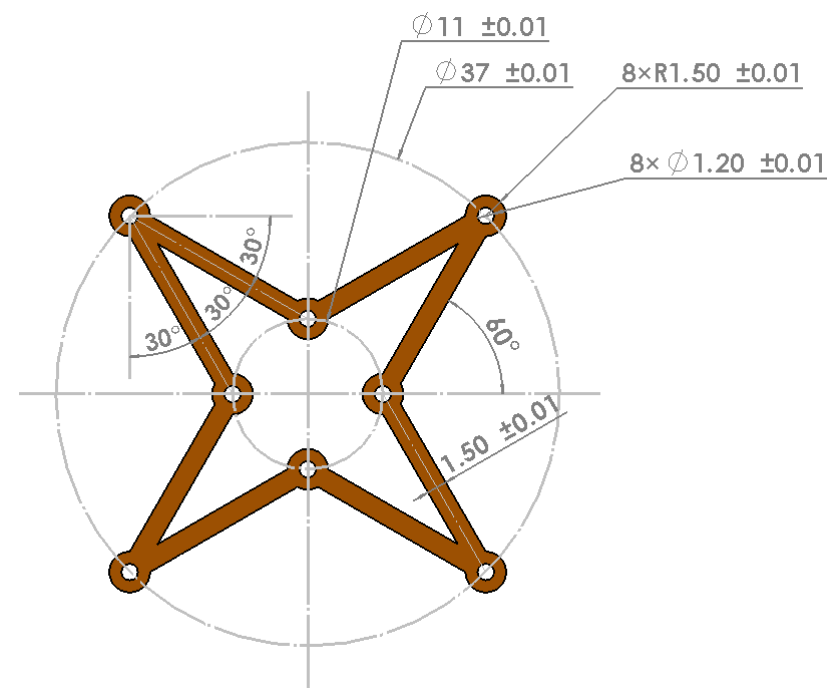

Figure 1. Four V-shaped leaf springs.

(2) Mask printing.

A high-precision mask is required to copy the designed pattern onto the beryllium bronze sheet. As a necessary intermediary, the precision of the mask directly determines the quality of the leaf springs. A professional film-printer of greater than $600 \times 600$ dot per inch (DPI) was used to print the pattern onto the unsmooth surface of a piece of film. When printing, a part of the pattern should be transparent to allow ultraviolet light to pass through and the remaining part should be black. A printed mask is shown in Figure 2.

(3) Pretreatment.

Beryllium bronze is oxidized when exposed in air for a long period of time and forms an oxidation film on the surface. It is difficult for the oxidation film to be corroded by the solution of $\mathrm{Na}_{2} \mathrm{~S}_{2} \mathrm{O}_{8}$. Therefore, we have to clear the oxidation film using the following pretreatment procedures: select a piece of beryllium bronze with an appropriate size, polish it on both sides using fine waterproof abrasive paper $(7000 \#)$ with a grift size of far less than $0.5 \mu \mathrm{m}$ and wipe off the powders produced on the surface. We then need to place the polished beryllium bronze sheet into a solution (SanNy 3111, 
2017, Dunhua, Inc., Shenzhen, China) for approximately $30 \mathrm{~s}$ to clean the oxidation film thoroughly. Finally, we need to rinse the beryllium bronze sheet using clean water and dry it. Images of an original beryllium bronze sheet and polished (using SanNy 3111) and cleaned sheets, are shown in Figure 3, respectively.

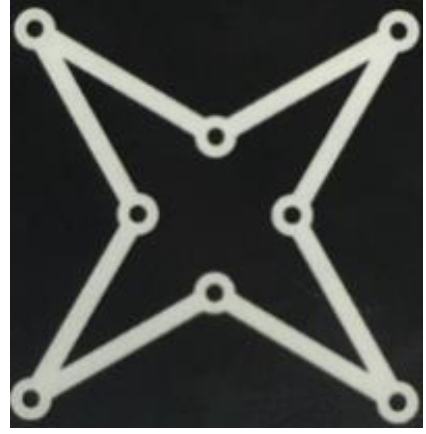

Figure 2. Printed mask.

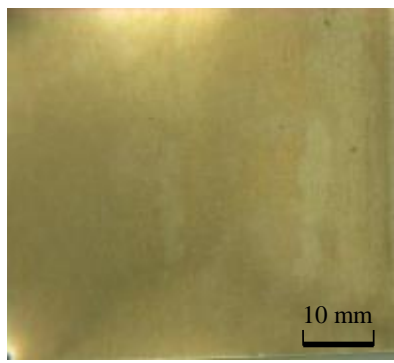

(a)

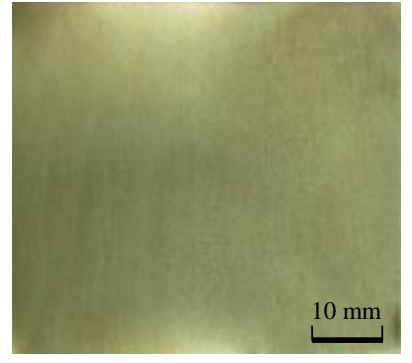

(b)

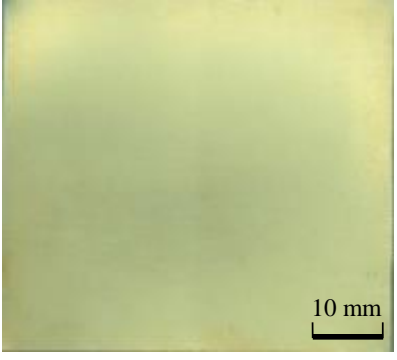

(c)

Figure 3. Images of beryllium bronze sheet: (a) original, (b) polished, (c) and cleaned.

(4) Pasting photo-sensory membrane.

The photo-sensory membrane (No.2138, 2017, Hemera, Inc., Shenzhen, China) we used was composed of a polyester, photoresist and polyethylene layers in sequence, as shown in Figure 4. The polyester layer is used to support and protect the photosensitive layer from being diffused when exposed to oxygen, which can destroy the light sensitivity of the photoresist. The polyethylene layer is used to cover the other side of the photosensitive layer to prevent it from being polluted by dust or other types of particles. The photoresist layer is the main body of the photosensitive membrane and is mostly made of a negative photosensitive material. The polyethylene layer needs to be torn off before attaching the photosensitive membrane onto the beryllium bronze sheet. The total thickness of the polyester layer and photoresist layer is $38 \mu \mathrm{m}$. Both sides of the beryllium bronze sheet need to be pasted with a photosensitive membrane and the photoresist layer should be attached to the sheet evenly and tightly with no bubbles. To affix the photoresist to the beryllium bronze sheet firmly, the beryllium bronze sheet with the photosensitive membrane needs to be pressed by two flat glasses and heated by a hot air blower. Figure 5 shows a beryllium bronze sheet pasted using a photo-sensory membrane.

(5) Exposure.

This process is used to place the prepared mask on the smooth surface of a beryllium bronze sheet with a photosensitive membrane and to make sure that the side with the printed pattern of the mask film is close to the beryllium bronze sheet. Both the beryllium bronze sheet and the mask film are clamped using two flat glasses. The next step is to expose the beryllium bronze sheet to a $365 \mathrm{~nm}$ 
ultraviolet light from a lamp of $48 \mathrm{~W}$ for approximately $2.5 \mathrm{~min}$ on both sides. The ultraviolet light can pass through the patterns of the mask film and solidify the photoresist. The color of the solidified photoresist is dark blue. The dark blue pattern shown in Figure 6 is what we want to achieve.

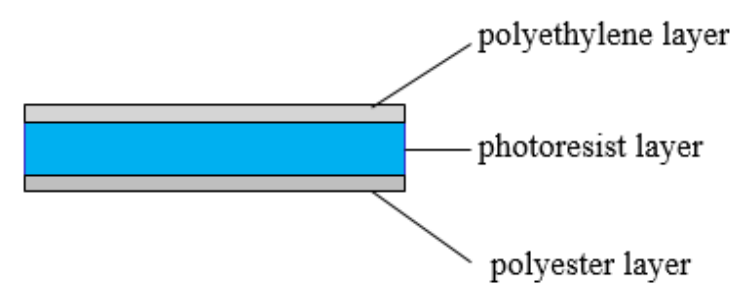

Figure 4. Sketch of photo-sensory membrane.

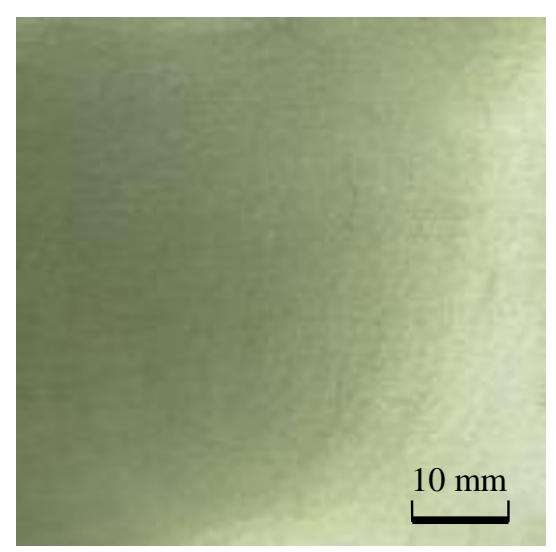

Figure 5. Beryllium bronze sheet with photo-sensory membrane.

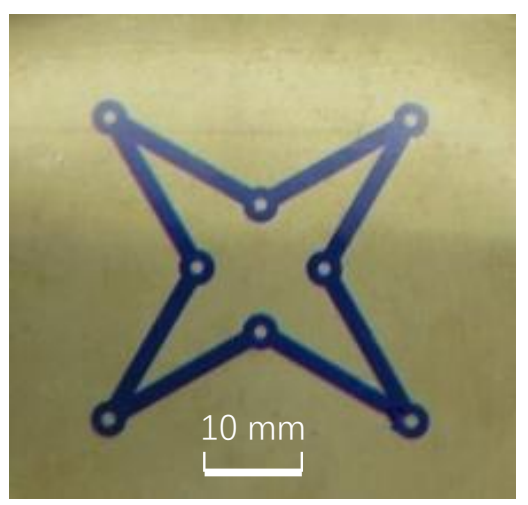

Figure 6. Exposed photo-sensory membrane.

(6) Development.

The developer, whose main component is sodium carbonate $\left(\mathrm{Na}_{2} \mathrm{CO}_{3}, 2017\right.$, Taishan Chemical Factory Co., Ltd., Taishan, China), should be watered at a mass ratio of 1:100. The proper temperature of the sodium carbonate solution should be $30-40{ }^{\circ} \mathrm{C}$. First, we must tear the polyester film of the exposed photo-sensory membrane off the beryllium bronze sheet and immerse it in the developer solution and then lightly scrub the patterned side of the beryllium bronze sheet with a brush to remove the unexposed photoresist. The final process is to rinse the beryllium bronze sheet using clean water and dry it again. 


\section{(7) Etching.}

The developed beryllium bronze sheet is placed into a $\mathrm{Na}_{2} \mathrm{~S}_{2} \mathrm{O}_{8}$ solution, the temperature of which is controlled and maintained at a stable value by using a thermostat water bath until the uncovered beryllium bronze is completely etched. Therefore, the leaf springs with a solidified photoresist will appear.

(8) Mold unloading.

The solidified photoresist on the leaf springs should be dissolved during this step. A special chemical for dissolving the solidified photoresist-the main component of which is sodium hydroxide (concentration $\mathrm{NaOH}, 2017$, Taishan Chemical Factory Co., Ltd., Taishan, China)—should be watered at a mass ratio of 1:50 beforehand. The proper temperature of the sodium hydroxide solution is approximately $50{ }^{\circ} \mathrm{C}$. The unfinished leaf spring is then soaked in the chemical solution, where it remains stable until the attached photoresists are cleared out, after which, the leaf spring is formed, as shown in Figure 7.

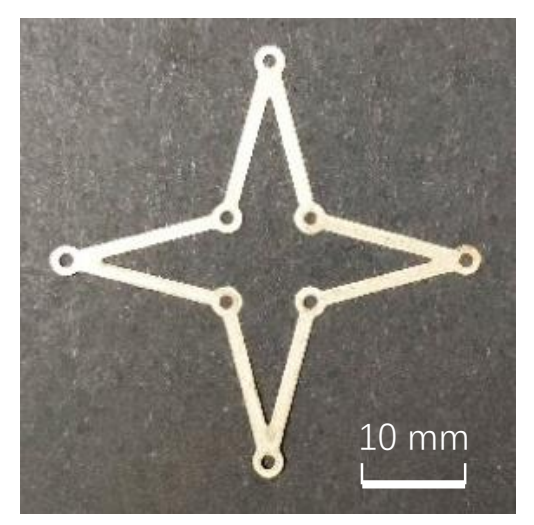

Figure 7. Finished leaf springs.

In term of the operational steps, this method (method A) is similar to the conventional photolithography (method B) [10]. However, there are essential differences between the two methods in practical, which include: (1) Method B adopts complicated photoresist coating and soft bake process to coat the photosensitive material on the wafer. Method A pastes the photo-sensory membrane on the beryllium bronze sheet directly by manual. (2) Method B uses scanning projection exposure method, which requires precision mechanical systems for assistance. Method A finish the exposure by irradiating with ultraviolet rays directly. (3) Method B usually uses plasma or sputtering process to do etching. Method A carries out the etching by sodium bicarbonate solution. (4) Method B has drying and wetting methods to unload the mold. Method A unloads the mold by sodium hydroxide solution.

\section{Process Parameter Optimization}

\subsection{Taguchi Experiments}

The precision of a fabricated pattern on a leaf spring can be evaluated based on the roundness of its circle or arc, the straightness of the lines and the offset of the position. The roundness and straightness reflect formation errors of the pattern. An offset reflects a size error, such as the diameter, width, or position. Many factors are related to these three indicators. However, we found that the key processing parameters are the concentration and temperature of the etchant solution and the exposure time based on analysis and experience. The concentration of the etchant solution directly affects the etching speed and $\mathrm{pH}$ of the solution, thereby influencing the quality of the leaf spring. The temperature of the etchant solution will also affect the etching speed. A lower temperature will 
slow down the reaction speed and a higher temperature will make the photoresist membrane fall off. An inadequate exposure time cannot solidify the photoresist completely. Instead, it will result in poor roundness or straightness and may even force the photo-sensory membrane to drop off. An overly long exposure time will bring about difficulties in the development and mold unloading and make the photoresist crisper. Therefore, proper experimental parameters are vital for us to fabricate high-precision leaf springs.

The Taguchi method was usually employed to obtain the optimal process parameters in different applications [16-20], which was also used in the present study. The roundness, straightness and offset of the leaf springs are regarded as three responsive variables. The three control factors are the concentration and temperature of the etchant solution and the exposure time. The levels of the control factors, presented in Table 2, were determined experimentally.

Table 2. Control factors and their levels.

\begin{tabular}{cccc}
\hline \multirow{2}{*}{ Level } & Factor A & Factor B & Factor C \\
\cline { 2 - 4 } & Concentration (Etchant: Water) & Temperature $\left({ }^{\circ} \mathbf{C}\right)$ & Time (min) \\
\hline 1 & $1: 3$ & 50 & 2 \\
2 & $1: 4$ & 60 & 2.5 \\
3 & $1: 5$ & 70 & 3 \\
\hline
\end{tabular}

The orthogonal table of L9 $\left(3^{3}\right)$ was used to design the test parameters. The parameters of each factor were filled into the orthogonal table according to the rules, as presented in Table 3.

Table 3. Orthogonal table of L9 $\left(3^{3}\right)$.

\begin{tabular}{cccc}
\hline L9 & Factor A & Factor B & Factor C \\
\hline 1 & 1 & 1 & 1 \\
2 & 2 & 1 & 2 \\
3 & 3 & 1 & 3 \\
4 & 2 & 2 & 1 \\
5 & 3 & 2 & 2 \\
6 & 1 & 2 & 3 \\
7 & 3 & 3 & 1 \\
8 & 1 & 3 & 2 \\
9 & 2 & 3 & 3 \\
\hline
\end{tabular}

The signal-to-noise $(\mathrm{S} / \mathrm{N})$ ratio is applied in the Taguchi method as the quality characteristic of choice. In the pursuit of smaller characteristics of the roundness, straightness and offset of the leaf springs, a smaller-the-better (STB) type characteristic was used as the objective function (Equation (2)) in this experiment.

$$
\eta=-10 \log \left(\frac{1}{n} \sum_{i=1}^{n} y_{i}^{2}\right)
$$

Here, $\eta$ is the signal to noise ratio $(\mathrm{S} / \mathrm{N}: \mathrm{dB}), n$ indicates the experimental period and $y_{i}$ can be the roundness, straightness, or offset of the leaf springs.

According to the experimental requirements of the orthogonal table, nine group experiments manufacturing the leaf springs shown in Figure 1 were carried out and repeated five times for each group. One of the holes on the leaf springs was selected to evaluate roundness. One of the branches on the leaf springs was selected to evaluate straightness and offset. The selected hole and branch were measured each time using an image profile projector (2011, MUMA200, 3DFamily, Inc., Nanjing China, with a resolution of $1 \mu \mathrm{m})$. The mean values of the roundness, straightness and offset are shown in Table 4 . The values of $\eta$ were also calculated and listed in Table 4. 
Table 4. Mean values of the response variable and its $\mathrm{S} / \mathrm{N}$ ratio.

\begin{tabular}{ccccccc}
\hline No. & Average Roundness $(\mu \mathrm{m})$ & $\eta_{R}$ & Average Straightness $(\mu \mathrm{m})$ & $\eta_{S}$ & Average Offset $(\mu \mathrm{m})$ & $\eta_{O}$ \\
\hline 1 & 70 & -37.80 & 21 & -26.93 & 15 & -23.77 \\
2 & 73 & -37.38 & 57 & -35.40 & 15 & -22.16 \\
3 & 54 & -33.67 & 21 & -27.39 & 6 & -16.19 \\
4 & 32 & -31.08 & 29 & -27.58 & 7 & -15.16 \\
5 & 54 & -34.99 & 50 & -34.74 & 12 & -22.32 \\
6 & 59 & -35.66 & 40 & -32.76 & 10 & -19.87 \\
7 & 41 & -33.16 & 37 & -31.65 & 9 & -16.26 \\
8 & 34 & -30.49 & 29 & -30.39 & 6 & -19.57 \\
9 & 44 & -32.76 & 34 & -30.81 & 10 & -19.53 \\
\hline
\end{tabular}

\subsection{Mean Value Analysis}

To find the optimal combination of the minimum roundness, straightness and offset, the mean values of the $\mathrm{S} / \mathrm{N}$ ratio at the same level for each factor were calculated as shown in Tables 3 and 4 . For example, the mean $\mathrm{S} / \mathrm{N}$ ratio for roundness at level 2 of factor $\mathrm{A}$ is calculated using

$$
\overline{\eta_{R A 2}}=\frac{1}{3}\left(\eta_{R}(2)+\eta_{R}(4)+\eta_{R}(9)\right)
$$

where $R$ and $A$ in the subscript denote the roundness and factor A, respectively. Factor $\mathrm{A}$ is set to level 2 only in experiments 2,4 and 9 . The mean $\mathrm{S} / \mathrm{N}$ ratios for all levels of all factors can be obtained in a similar way, as shown in Table 5.

Table 5. Mean values at the same level of each factor and variable.

\begin{tabular}{ccccc}
\hline \multirow{2}{*}{ Response Variables } & \multirow{2}{*}{ Level } & \multicolumn{3}{c}{ Mean S/N Ratio } \\
\cline { 3 - 5 } & & Factor A & Factor B & Factor C \\
\hline \multirow{2}{*}{ roundness } & 1 & -36.28 & -34.01 & -34.65 \\
& 2 & -33.91 & -34.29 & -33.74 \\
& 3 & -32.14 & -34.03 & -33.94 \\
\hline \multirow{2}{*}{ straightness } & 1 & -29.91 & -28.72 & -30.03 \\
& 2 & -31.69 & -33.51 & -31.26 \\
& 3 & -30.95 & -30.32 & -31.26 \\
\hline \multirow{2}{*}{ offset } & 1 & -20.71 & -19.47 & -20.30 \\
& 2 & -19.45 & -20.25 & -18.96 \\
& 3 & -18.72 & -19.33 & -19.33 \\
\hline
\end{tabular}

According to the Taguchi principle, the maximum $\mathrm{S} / \mathrm{N}$ ratio value should be considered when determining the main levels and main factors. From Table 5, we can see that the combination of factor levels $\left(A_{3}, B_{1}, C_{2}\right),\left(A_{1}, B_{1}, C_{1}\right)$ and $\left(A_{3}, B_{3}, C_{2}\right)$ contribute to a minimization of the roundness, straightness and offset, respectively. Using the optimal factor-level combination, three groups experiments were conducted separately for the minimum roundness, straightness and offset, with each group repeated five times. Table 6 shows the results.

Table 6. Measured results of three variables.

\begin{tabular}{ccccccc}
\hline No. & $\mathbf{1}$ & $\mathbf{2}$ & $\mathbf{3}$ & $\mathbf{4}$ & $\mathbf{5}$ & Combination of Factor Levels \\
\hline roundness $(\mu \mathrm{m})$ & 52 & 46 & 33 & 38 & 49 & $\mathrm{~A}_{3}, \mathrm{~B}_{1}, \mathrm{C}_{2}$ \\
straightness $(\mu \mathrm{m})$ & 22 & 15 & 30 & 16 & 22 & $\mathrm{~A}_{1}, \mathrm{~B}_{1}, \mathrm{C}_{1}$ \\
offset $(\mu \mathrm{m})$ & 9 & 10 & 8 & 10 & 9 & $\mathrm{~A}_{3}, \mathrm{~B}_{3}, \mathrm{C}_{2}$ \\
\hline
\end{tabular}


Plugging the results shown in Table 6 into Equation (2), we can obtain the $\mathrm{S} / \mathrm{N}$ ratio $(\eta)$ of the roundness, straightness and offset, shown in Table 7 . The expectations of the $\mathrm{S} / \mathrm{N}$ ratio $\left(\eta_{R O}, \eta_{S O}\right.$ and $\left.\eta_{O O}\right)$ of the roundness, straightness and offset can be calculated as

$$
\begin{gathered}
\eta_{R O}=\overline{\eta_{R}}+\left(\overline{\eta_{R A 3}}+\overline{\eta_{R B 1}}+\overline{\eta_{R C 2}}\right)-3 \overline{\eta_{R}} \\
\eta_{S O}=\overline{\eta_{S}}+\left(\overline{\eta_{S A 1}}+\overline{\eta_{S B 1}}+\overline{\eta_{S C 1}}\right)-3 \overline{\eta_{S}} \\
\eta_{O O}=\overline{\eta_{O}}+\left(\overline{\eta_{O A 3}}+\overline{\eta_{O B 3}}+\overline{\eta_{O C 2}}\right)-3 \overline{\eta_{O}}
\end{gathered}
$$

where $\eta_{R}, \eta_{S}$ and $\eta_{O}$ are the mean values of the $S / N$ ratio shown in Table 3 . Here, the $R, S$ and $O$ subscripts denote the roundness, straightness and offset, respectively. In addition, the $A, B$ and $C$ subscripts indicate factors A, B and C, respectively and 1,2 and 3 represent levels 1,2 and 3. The relative error can also be calculated using Equation (7). Both the expectations and relative errors are presented in Table 7 . From Table 7, we can see that all of the relative errors are less than $10 \%$. Thus, the effectiveness of the factor-level combinations obtained is verified.

$$
E_{R}=\frac{\left|\eta_{O}-\eta\right|}{\left|\eta_{O}\right|} \times 100 \%
$$

Table 7. S/N ratio and its relative error.

\begin{tabular}{cccc}
\hline Item & $\eta_{O}$ & $\eta$ & Relative Error (\%) \\
\hline roundness & -31.67 & -33.05 & 4.36 \\
straightness & -26.95 & -26.97 & 0.07 \\
offset & -17.95 & -19.59 & 9.13 \\
\hline
\end{tabular}

\subsection{Variance Analysis}

Three factor-level combinations aiming at roundness, straightness and offset were obtained using a mean value analysis. We still need to calculate the contributions of each factor for the roundness, straightness and offset through a variance analysis, so as to achieve the final optimal process parameters. The variance (SS) for each variable and each control factor was calculated using Equation (8). The variances and contributions of the control factor for each variable were shown in Table 8.

$$
S S_{V F}=3 \sum_{i=1}^{3}\left(\overline{\eta_{V F i}}-\overline{\eta_{V}}\right)^{2}
$$

\begin{tabular}{|c|c|c|c|c|c|c|}
\hline \multirow{2}{*}{ Control Factors } & \multicolumn{2}{|c|}{ Roundness } & \multicolumn{2}{|c|}{ Straightness } & \multicolumn{2}{|c|}{ Offset } \\
\hline & $S S_{R}$ & $\%$ & $s S_{S}$ & $\%$ & $S S_{O}$ & $\%$ \\
\hline A & 25.97 & 94.5 & 4.83 & 11.1 & 6.14 & 57.5 \\
\hline B & 0.14 & 0.5 & 35.68 & 81.9 & 1.67 & 15.7 \\
\hline C & 1.37 & 5.0 & 3.05 & 7.0 & 2.86 & 26.8 \\
\hline sum & 27.48 & 100 & 43.56 & 100 & 10.67 & 100 \\
\hline
\end{tabular}

where $V$ indicates a variable, which can be roundness, straightness, or offset; $F$ indicates the factor, which can be A, B, or C; $i$ is the sequence number of the factor level; and $\overline{\eta_{V}}$ and $\overline{\eta_{V F i}}$ are as shown in Tables 3 and 4, respectively.

Table 8. Contributions of the parameters.

From Table 8, we can see that the dominant control factor for roundness is factor A (concentration of etchant solution), the dominant control factor for straightness is factor $\mathrm{B}$ (temperature of the etchant solution) and the control factor's order of importance for an offset is A, C and B in sequence. Combining 
the factor-level combinations above, we can see that the optimal process parameters are $A_{3}, B_{1}$ and $\mathrm{C}_{2}$. In other words, the best mass ratio of etchant to water is $1: 5$, the best temperature of the etchant solution is $50^{\circ} \mathrm{C}$ and the best exposure time is $2 \mathrm{~min}$ and $30 \mathrm{~s}$.

\section{Experimental Results}

\subsection{Leaf Springs with Complex Pattern}

Using the optimal process parameters obtained through Taguchi experiments, different leaf springs with complex patterns were fabricated using the proposed chemical etching method, as shown in Figure 8. The thinnest line width is less than $0.5 \mathrm{~mm}$. The leaf springs are also very flat and smooth without any warping or deformations. It is very difficult for wire-EDM to fabricate these complex leaf springs with thin lines and many disconnected regions. First, the thinnest width of the line wire-EDM that can be achieved is approximately $1 \mathrm{~mm}$. A through-hole then needs to be drilled to allow a wire to pass through when cutting a newly disconnected region using wire-EDM. The more disconnected regions the leaf spring has, the longer the time, the higher the cost and the more energy consumption required. Finally, warping and deformation of the sheet are inevitable owing to the step-by-step process using.

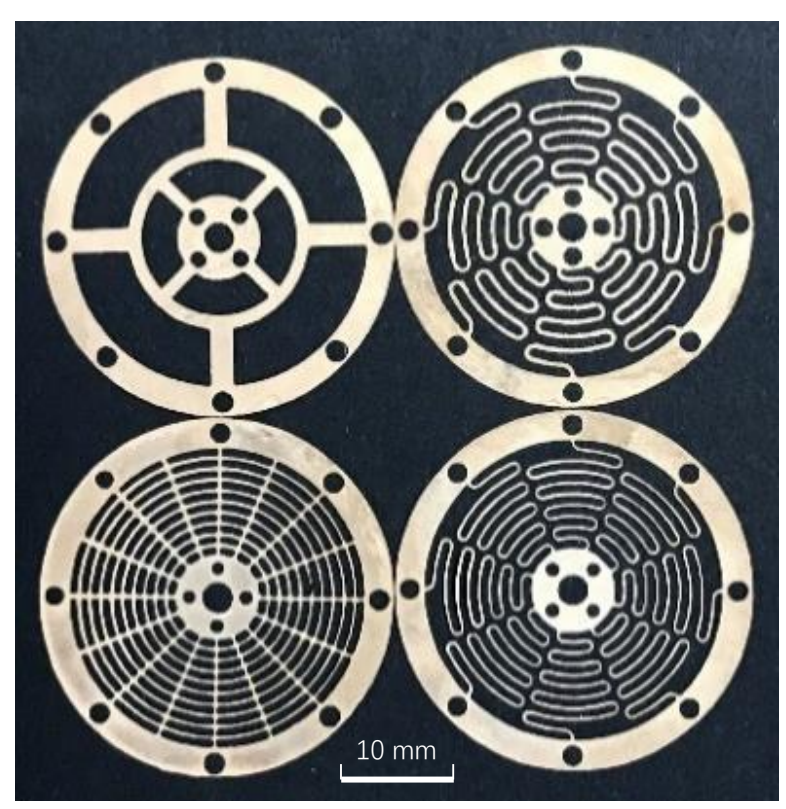

Figure 8. Leaf springs with a complex pattern.

\subsection{Quality Measurements of Leaf Springs}

Using the optimal process parameters obtained through the Taguchi method, the four V-shaped leaf spring Figure 1 shows was fabricated five times using an etching method. As a comparison, the same leaf spring was also fabricated five times using the wire-EDM method [21]. The images of a ring and line from the leaf springs fabricated using these two methods are shown in Figure 9. Their roundness, straightness and offset were measured using a MUMA 200 (2011, 3DFamily, Inc., Nanjing China), the results of which are provided in Tables 9-11, respectively. 


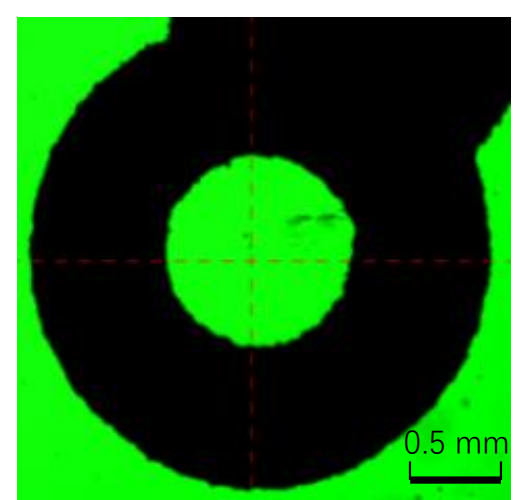

(a)

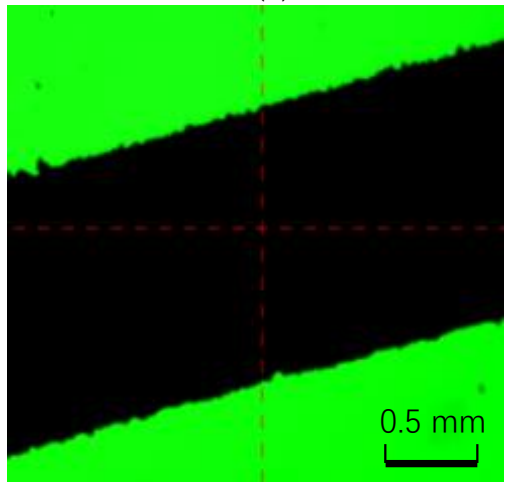

(c)

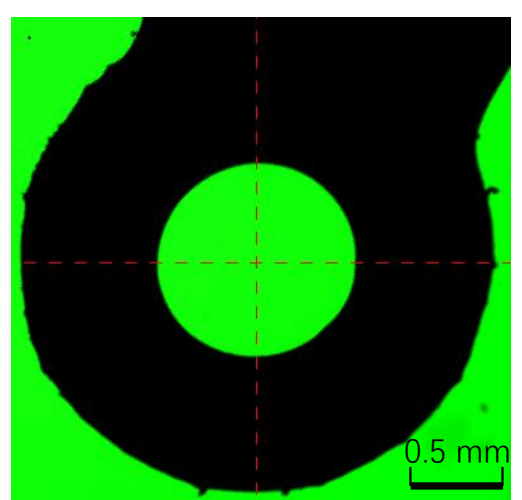

(b)

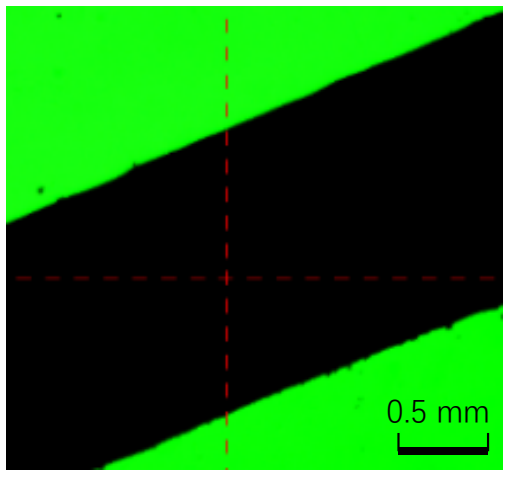

(d)

Figure 9. A ring of a leaf spring using (a) wire-EDM, (b) etching and a line of a leaf spring using, (c) wire-EDM and (d) etching.

Table 9. Results of error in roundness.

\begin{tabular}{cccc}
\hline No. & Etching $(\mu \mathrm{m})$ & Wire-EDM $(\mu \mathrm{m})$ & Difference $(\mu \mathrm{m})$ \\
\hline 1 & 4 & 31 & 27 \\
2 & 43 & 63 & 20 \\
3 & 37 & 40 & 3 \\
4 & 25 & 63 & 38 \\
5 & 21 & 78 & 57 \\
mean value & 26.0 & 55.0 & 29.0 \\
\hline
\end{tabular}

Table 10. Results of error in straightness.

\begin{tabular}{cccc}
\hline No. & Etching $(\mu \mathrm{m})$ & Wire-EDM $(\mu \mathrm{m})$ & Difference $(\mu \mathrm{m})$ \\
\hline 1 & 27 & 45 & 18 \\
2 & 36 & 76 & 40 \\
3 & 20 & 49 & 29 \\
4 & 16 & 88 & 72 \\
5 & 35 & 76 & 41 \\
mean value & 26.8 & 66.8 & 40.0 \\
\hline
\end{tabular}

Table 11. Results of error in offset.

\begin{tabular}{cccc}
\hline No. & Etching $(\mu \mathrm{m})$ & Wire-EDM $(\mu \mathrm{m})$ & Difference $(\mu \mathrm{m})$ \\
\hline 1 & 7 & 17 & 10 \\
2 & 6 & 15 & 9 \\
3 & 4 & 19 & 15 \\
4 & 4 & 23 & 19 \\
5 & 7 & 20 & 13 \\
mean value & 5.6 & 18.8 & 13.2 \\
\hline
\end{tabular}


We can see from Figure 9 that the edge of the leaf spring developed using an etching process is much smoother than that using wire-EDM. From the measured data in Tables 9-11, we can conclude that the roundness, straightness and offset of the leaf springs achieved through etching are much better than those achieved using wire-EDM.

The measurement uncertainty for the leaf springs is mainly composed of five parts. The first one is the measurement repeatability which reflecting the contributions from random errors. The second one is the indication error which reflecting the contributions from resolution, evaluation algorithm and so on. The third one is the attitude error which reflecting the contributions from the different attitudes of the leaf springs. The forth one is the alignment error. The fifth one is the contributions from temperature and humidity which can be ignored when evaluating the form errors. One of the holes, and a rectangle leaf from the manufactured leaf spring, shown in Figure 1 were measured 10 times, using the proposed method, in a standard measurement environment $\left(u_{5}=0\right)$. Table 12 shows the measurement results and standard uncertainties $\left(u_{1}\right)$. From Table 12 , we can also see that the manufacturing errors of both the diameter and the line width of the leaf springs shown in Figure 1 are less than $9 \mu \mathrm{m}$. The indication errors of the image profile projector we used were investigated by measuring a calibration mask in different angles, the indication errors were shown in Table 13. Considering that the maximum indication errors include the attitude errors, the uncertainties $\left(u_{23}\right)$ contributed from indication errors and attitude errors have been obtained and shown in Table 13. The uncertainties $\left(u_{4}\right)$ contributed by alignment errors can be neglected because telecentric lenses were used in the image profile projector. Therefore, the measurement uncertainties shown in Table 14 have been achieved using the Equation of $U=\sqrt{u_{1}^{2}+u_{23}^{2}}$.

Table 12. Results of repeated measurement.

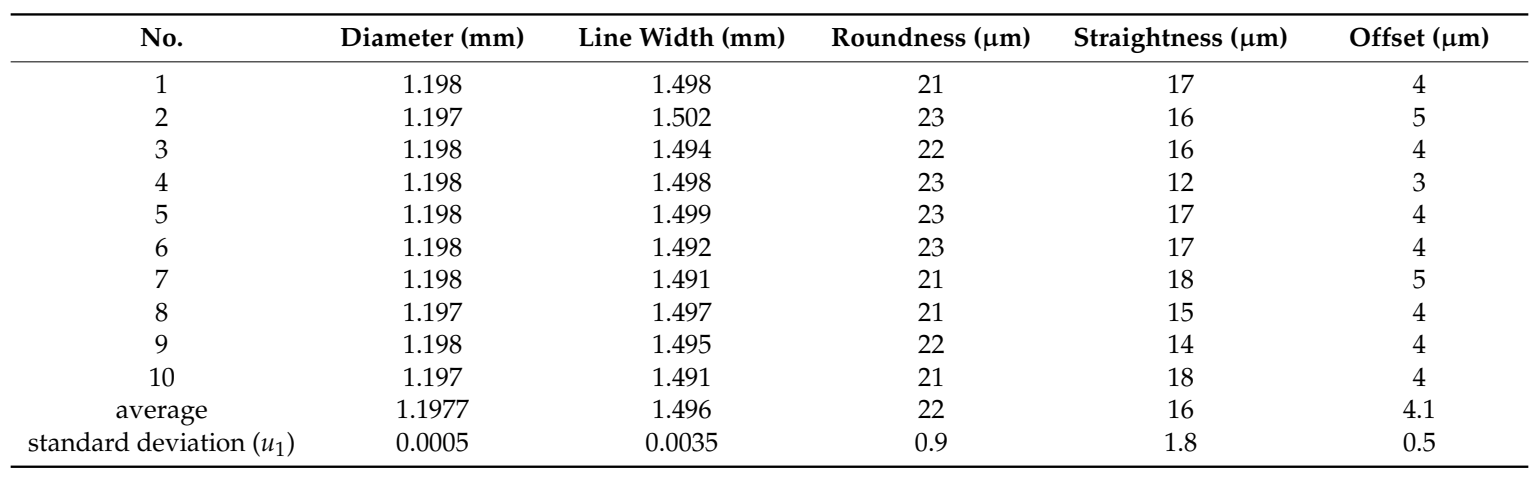

Table 13. Results of indication errors in different attitudes.

\begin{tabular}{cccccc}
\hline Angle & Diameter $(\mu \mathrm{m})$ & Line Width $(\mu \mathrm{m})$ & Roundness $(\mu \mathrm{m})$ & Straightness $(\mu \mathrm{m})$ & Offset $(\mu \mathrm{m})$ \\
\hline $60^{\circ}$ & 1 & 2 & 1 & 1 & 1 \\
$120^{\circ}$ & 2 & 2 & 2 & 1 & 1 \\
$180^{\circ}$ & 2 & 1 & 2 & 2 & 1 \\
$240^{\circ}$ & 2 & 1 & 3 & 1 & 2 \\
$300^{\circ}$ & 1 & 3 & 1 & 1 & 1 \\
$360^{\circ}$ & 2 & 2 & 2 & 2 & 2 \\
maximum value $(\triangle)$ & 2 & 3 & 1.7 & 1.2 & 1.2 \\
$u_{23}(=\Delta / \sqrt{3})$ & 1.2 & 1.7 & & & \\
\hline
\end{tabular}

Table 14. Results of measurement uncertainties.

\begin{tabular}{cccccc}
\hline Item & Diameter & Line Width & Roundness & Straightness & Offset \\
\hline$U(\mu \mathrm{m})(k=2)$ & 2.6 & 7.8 & 3.8 & 4.3 & 2.6 \\
\hline
\end{tabular}




\subsection{Leaf Spring Performance}

Leaf spring is a key component of a micro/nano probe and determines the measurement precision of the probe to a great extent. The leaf spring shown in Figure 1 was manufactured by chemical etching method and applied to our probe [4]. Both the floating plate and the supporting ring connected to the leaf spring have a dimensional tolerance of $0.1 \mu \mathrm{m}$. The assembling accuracy of the probe on the leaf springs are controlled by the manufacturing accuracy since the symmetric design of the leaf spring and its connected attachments. An experimental setup shown in Figure 10 were built and the probe was tested. The probe was assembled in a frame of stand. A $2 \mathrm{~mm} \times 2 \mathrm{~mm}$ square hole formed by four 0 grade gauge blocks with same horizontal sizes of $30 \mathrm{~mm} \times 9 \mathrm{~mm}$ and thicknesses of $2 \mathrm{~mm}, 2 \mathrm{~mm}$, $1.6 \mathrm{~mm}$ and $1.7 \mathrm{~mm}$ respectively, was used to contact the probe tip in lateral directions. As for the inner surfaces of the square hole, two parallel surfaces of them are the reference planes of the gauge block but the other two are not. Only the reference planes of the gauge block were used to contact the probe tip in the experiment. Therefore, rotation for the probe is required when changing a contact direction in horizontal. A round dial with an accuracy of 0.5 degree was equipped on the rotating shaft of the probe, so as to index the rotated angle of the probe. A 2D linear stage was used to change the initial position of the square hole manually. A high-precision 3D nano-positioning stage made by Physik Instrumente (2013, PI, model P-561.3 CD with a repeatability of $2 \mathrm{~nm}$ and a distance of travel of $100 \mu \mathrm{m}$ in each direction, Germany) was used as a reference with an interval of $2 \mu \mathrm{m} .10$ measurements were repeated at each point. The results (X2 and Y2) were shown in Figure 11. From Figure 11, we can see that the probe's measurement standard deviation is about $16 \mathrm{~nm}$.

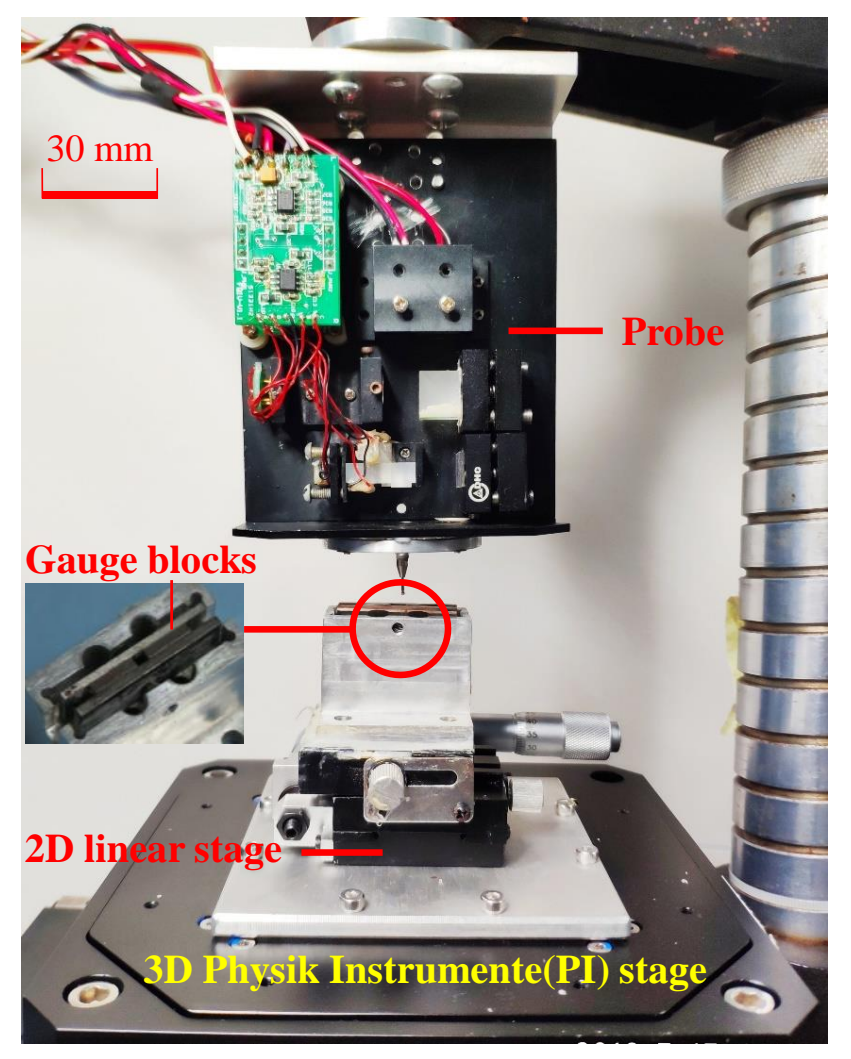

Figure 10. Photograph of the experimental setup.

In comparison, the same leaf spring was manufactured by wire-EDM, used in the same probe and similar experiments were conducted by the same experimental setup. The results (X1 and Y1) were also shown in Figure 11. In this case, the measurement standard deviation of the probe is about $30 \mathrm{~nm}$. Compared with the leaf springs fabricated by the proposed method, the ones fabricated by EDM have 
evident thermal deformation and poor edge uniformity, which cause an anisotropic and lead to worse measurement standard deviation of the probe. The experimental results demonstrate that the chemical etching method is a better choice in fabricating high-precision leaf springs for a micro/nano probe.

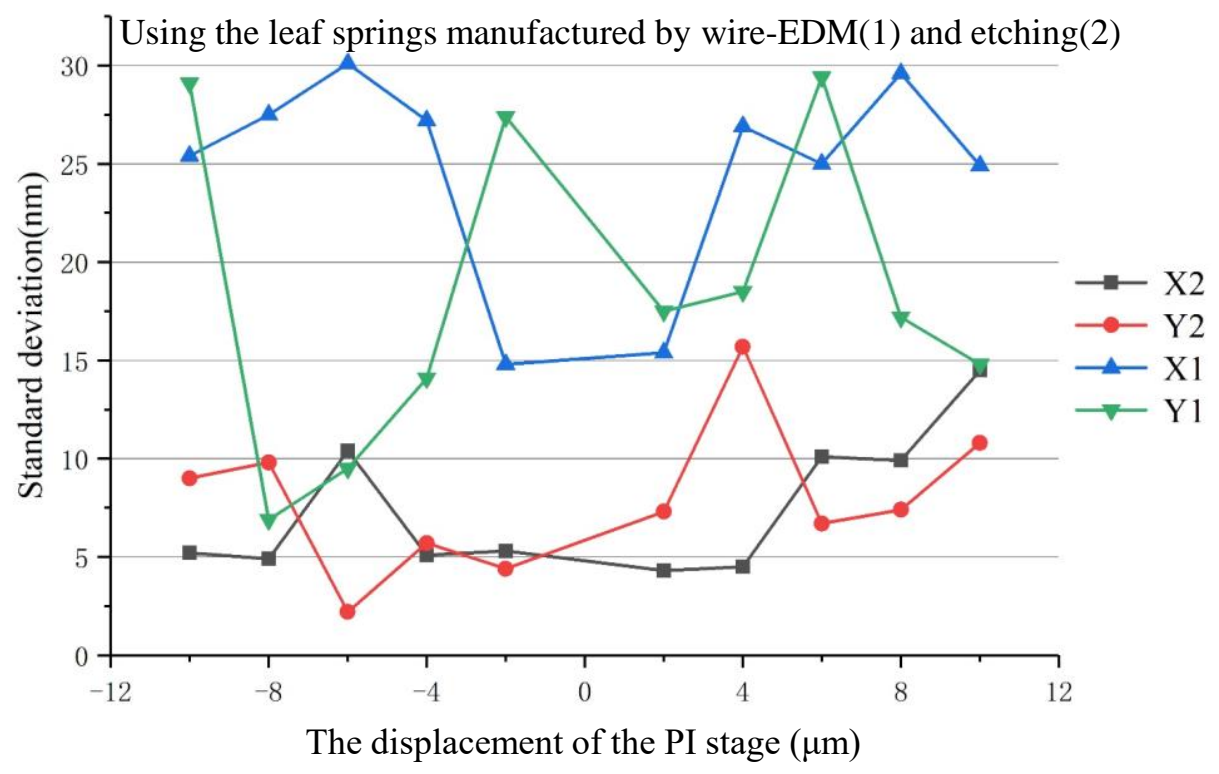

Figure 11. Results of the experiments.

\section{Conclusions}

A chemical etching method was proposed to fabricate the leaf springs for a CMM probe in this paper. The optimal process parameters were obtained using the Taguchi method, which includes a mass ratio of etchant to water of $1: 5$, temperature of the etchant solution of $50{ }^{\circ} \mathrm{C}$ and an exposure time of $2 \mathrm{~min}$ and $30 \mathrm{~s}$. Compared with the wire-EDM method, this method has the advantages of high precision, no deformations, easy fabrication of complex patterns, low energy consumption, low cost and easy operation. This manufacturing method can be used to fabricate different high-precision springs for CMM probes and other types of measurement equipment.

Author Contributions: Conceived the Method and Wrote the Paper, R.-J.L.; Designed and Performed the Taguchi Experiments, P.-Y.W.; Improved the Experimental Results by Using a Thermostat Water Bath, D.-D.L.; Edited the Manuscript, K.-C.F.; Performed some Confirmatory Experiments, F.-F.L. and L.-J.C.; Designed the Confirmatory Experiments, Q.-X.H.

Funding: This study was funded by the National Natural Science Foundation of China $(51675157,51475131)$.

Conflicts of Interest: The authors declare no conflict of interest.

\section{References}

1. Liu, C.; Huang, J.B.; Zhu, Z.; Jiang, F. A micromachined flow shear-stress sensor based on thermal transfer principles. J. Microelectromech. Syst. 1999, 8, 90-99. [CrossRef]

2. Alshehri, A.; Kraft, M.; Gardonio, P. Two-mass MEMS velocity sensor: Internal feedback loop design. IEEE Sens. J. 2013, 13, 1003-1011. [CrossRef]

3. Li, R.J.; Fan, K.C.; Miao, J.W.; Huang, Q.X.; Tao, S.; Gong, E.M. An analogue contact probe using a compact 3D optical sensor for micro/nano coordinate measuring machines. Meas. Sci. Technol. 2014, 25, 094008. [CrossRef]

4. Li, R.J.; Fan, K.C.; Huang, Q.X.; Zhou, H.; Gong, E.M.; Xiang, M. A long-stroke 3D contact scanning probe for micro/nano coordinate measuring machine. Precis. Eng. 2016, 43, 220-229. [CrossRef]

5. Li, R.J.; Xiang, M.; He, Y.X.; Fan, K.C.; Cheng, Z.Y.; Huang, Q.X.; Zhou, B. Development of a high-precision touch-trigger probe using a single sensor. Appl. Sci. 2016, 6, 86. [CrossRef] 
6. Liu, W.; Cai, Q.; Guo, X.; Chen, Y.; Wang, L. Three dimensional micro-structure soft lithography technology. Chin. J. Sens. Actuators 2002, 15, 136-139.

7. Tajiri, K.; Nakamura, T.; Kabeya, Z.; Yamanaka, Y.; Naito, F. Development of an electroformed copper lining for accelerator components. Electrochim. Acta. 2001, 47, 143-148. [CrossRef]

8. Schindler, A.; Haensel, T.; Flamm, D. Ion beam and plasma jet etching for optical component fabrication. J. Soc. Photo-Opt. Instrum. Eng. 2001, 4440, 217-227. [CrossRef]

9. Bodeux, R.; Michau, D.; Josse, M.; Maglione, M. Dielectric properties of tetragonal tungsten bronze films deposited by RF magnetron sputtering. Solid State Sci. 2014, 38, 112-118. [CrossRef]

10. Chen, Y.F. Nanofabrication by electron beam lithography and its applications: A review. Microelectron. Eng. 2015, 135, 57-72. [CrossRef]

11. Li, Y.H.; Ding, G.F.; Mao, H.P.; Zhang, Y.H. The Development of microelectroforming process of LIGA/Quasi-LIGA technology. Electron. Process Technol. 2005, 26, 1-5.

12. Kelly, P.J.; Arnell, T.D. Magnetron sputtering: A review of recent developments and applications. Vacuum 2000, 56, 159-172. [CrossRef]

13. Ho, K.H.; Newman, S.T.; Rahimifard, S.; Allen, R.D. State of the art in wire electrical discharge machining (WEDM). Int. J. Mach. Tool Manuf. 2004, 44, 1247-1259. [CrossRef]

14. Jiang, H.H. Development and forecast of the laser processing technology application. Optoelectron. Technol. Inf. 2001, 4, 1-10.

15. Li, R.J.; Fan, K.C.; Zhou, H.; Wang, N.; Huang, Q.X. Elastic mechanism design of the CMM contact probe. In Proceedings of the Sixth International Symposium on Precision Mechanical Measurements, Guiyang, China, 10 August 2013; SPIE: Bellingham, WA, USA.

16. Lan, T.S.; Chuang, K.C.; Chen, Y.M. Optimization of machining parameters using fuzzy Taguchi method for reducing tool wear. Appl. Sci. 2018, 8, 1011. [CrossRef]

17. Krzysztof, M.; Katarzyna, M.; Sebastian, B.; Jakub, B.; Alicja, T.; Marta, M.; Martyna, L.; Szymon, P.; Beata, G. Optimization of a culture medium using the Taguchi approach for the production of microorganisms active in odorous compound removal. Appl. Sci. 2017, 7, 756. [CrossRef]

18. Vigneashwara, P.; Wahyu, C.; Tegoeh, T.; Gunasekaran, P. Predictive modelling and analysis of process parameters on material removal characteristics in abrasive belt grinding process. Appl. Sci. 2017, 7, 363.

19. Do, T.V.; Hsu, Q.C. Optimization of minimum quantity lubricant conditions and cutting parameters in hard milling of AISI H13 steel. Appl. Sci. 2016, 6, 83. [CrossRef]

20. Nguyen, H.T.; Hsu, Q.C. Surface roughness analysis in the hard milling of JIS SKD61 alloy steel. Appl. Sci. 2016, 6, 172. [CrossRef]

21. Fostex Manual CNC Wire Cut FZC Series Machine. Available online: https://www.indiamart.com/ proddetail/cnc-wire-cut-fzc-series-machine-15574858988.html (accessed on 25 July 2018). 